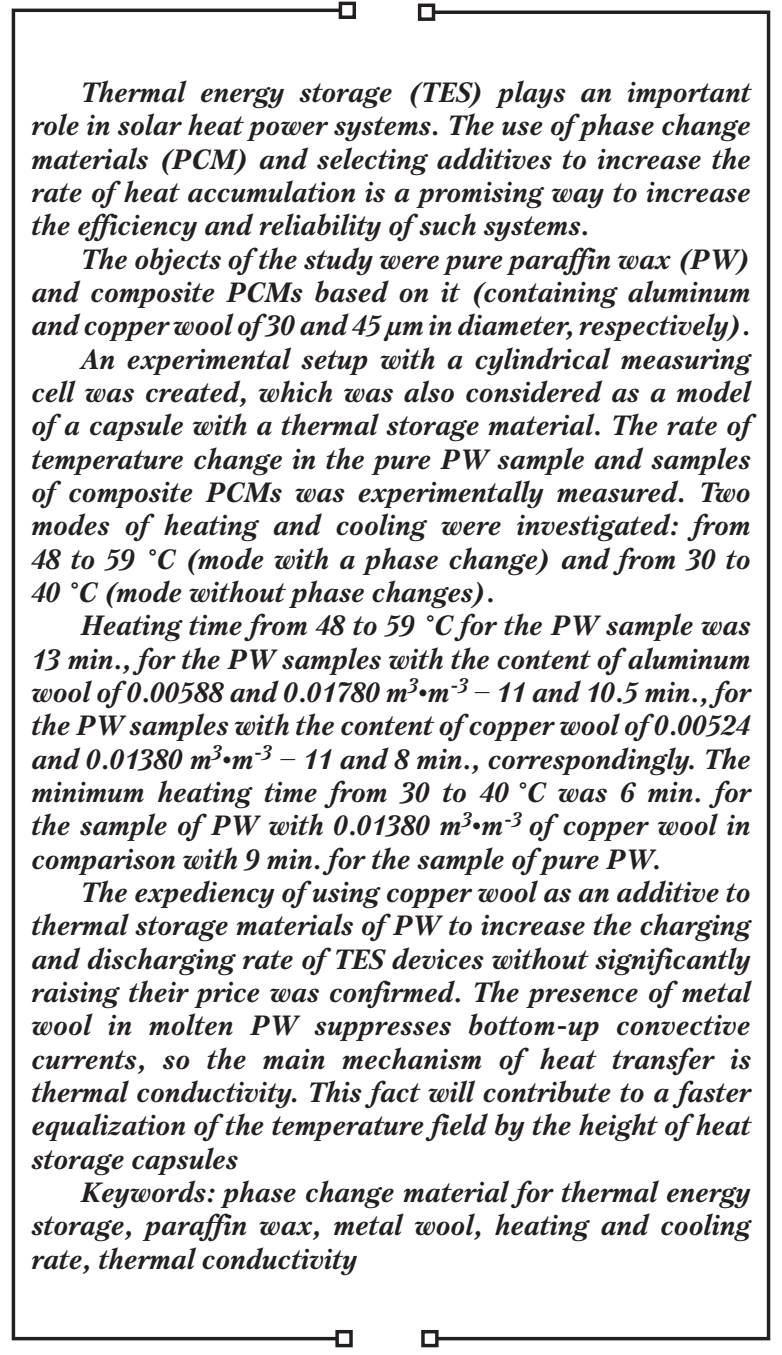

UDC 536.42:543.57

DOI: $10.15587 / 1729-4061.2021 .239065$

\section{THE EFFECT OF METAL WOOL ON THE CHARGING AND DISCHARGING RATE OF THE PHASE TRANSITION THERMAL STORAGE MATERIAL}

\author{
Olga Khliyeva \\ Corresponding author \\ Doctor of Technical Sciences, Professor* \\ E-mail: khliyev@ukr.net \\ Vitaly Zhelezny \\ Doctor of Technical Sciences, Professor* \\ Aleksey Paskal \\ Postgraduate Student* \\ Yan a H lek \\ Postgraduate Student* \\ D m y tro Ivchenko \\ Lecturer* \\ *Department of Thermophysics and Applied Ecology \\ Odessa National Academy of Food Technologies \\ Kanatna str., 112, Odessa, Ukraine, 65036
}

Received date 11.07.2021

Accepted date 23.08.2021

Published date 27.08.2021
How to Cite: Khliyeva, O., Zhelezny, V., Paskal, A., Hlek, Y., Ivchenko, D. (2021). The effect of metal wool on the charging and discharging rate of the phase transition thermal storage material. Eastern-European Journal of Enterprise Technologies, 4 (5 (112)), 12-20. doi: https://doi.org/10.15587/1729-4061.2021.239065

\section{Introduction}

Thermal energy storage (TES) plays an important role in solar heat power systems. The implementation of TES systems may overcome the time discrepancy between incoming solar energy and demanding thermal energy. Among various TES methods, the effectiveness of accumulating latent heat by using phase change materials (PCMs) is widely known due to such advantages as high energy storage density and its isothermal operating characteristics during the solidification and melting processes (charging/discharging) [1].

Paraffin wax (PW) is considered an attractive material for heat storage applications [2]. PWs are cheap, ecologically harmless, and non-toxic. Thermal storage PCMs are characterized by high latent heat storage capacities over a narrow temperature range, corrosion resistance to the main construction materials of TES systems, but they have a low thermal conductivity.

Some researches aimed to eliminate this problem and focused on finding ways to increase the thermal conductivity of existing thermal storage PCMs. Several approaches are considered: installing metal fins in TES devices [3] or capsules with thermal storage PCM [4], adding nanoparticles [5] to thermal storage PCM, including nanoparticles of metal oxide [6], carbon nanotubes and nanofibers [7-9], introduction of thermal storage PCMs into highly thermally conductive structures made from expanded graphite [9] or metal matrixes [10], adding highly thermally conductive metal wool [3,11,12], etc. Thus, the investigation aimed at increasing the thermal conductivity of thermal storage PCMs is currently relevant. It is known that an increase in thermal conductivity will contribute to an increase in the reaction rate of the system to thermal influences and, thus, the overall efficiency of TES systems [10].

\section{Literature review and problem statement}

There are two approaches to solve the problem of increasing charging and discharging rates of the TES device with PCM. The first one is to increase the heat exchange surface of the TES device using finning [3]. In addition, fins can be installed in capsules with thermal storage material [4].

In [3], the experimental study and subsequent comparison for two methods of improving the heat transfer in TES 
systems using latent heat of materials were performed: installation of aluminum fins in the TES device or laying metal wool from low-grade carbon steel. As PCM, n-octadecane was used. The results obtained provided evidence that the investigated metal wool cannot compete against aluminum fins. However, it was shown that metal wool is a pretty cheap solution that can improve the charging process up to $14 \%$ due to heat transfer enhancement compared to similar systems without using any fins or metal wool. At the same time, the study did not contain any attempts to use metal wool with high thermal conductivity (for example, copper or aluminum).

In [4], fins were used to improve the heat transfer rate in capsules with thermal storage PCMs. The results have shown that fins of straight design contribute to a more significant increase in the heat transfer coefficient than other constructions, especially when the number of fins is small (up to 6) and the thermal conductivity of the capsule material is low. However, the design of capsules with fins is quite complex and, consequently, expensive.

The use of fins is a well-known heat transfer enhancement method, but implementation cost and high metal intensity are the main drawbacks. In addition, the presence of metal fins leads to a decrease in the mass of PCM in the TES device and, as a consequence, the energy capacity.

The second approach is to increase the thermal conductivity of the base thermal storage PCM with the help of the addition of various highly thermally conductive structures.

In [6], the thermal properties of PCM based on PW were investigated under the influence of $\mathrm{CuO}$ and $\mathrm{Al}_{2} \mathrm{O}_{3}$ nanoparticles at low mass fractions (1.0\%). An improvement of the PW thermal conductivity containing $\mathrm{CuO}$ nanoparticles was estimated as $60.56 \%$, which is $21.12 \%$ higher than for the $\mathrm{PW} / \mathrm{Al}_{2} \mathrm{O}_{3}$ system. The reduction in supercooling was observed both for the $\mathrm{PW} / \mathrm{CuO}$ and $\mathrm{PW} / \mathrm{Al}_{2} \mathrm{O}_{3}$ systems in comparison with pure PW. A $4.3 \%$ and a $5.9 \%$ decrement in the latent heat of melting and freezing, correspondingly, was observed when adding $\mathrm{CuO}$ nanoparticles in $\mathrm{PW}$ and a little bit less when adding $\mathrm{Al}_{2} \mathrm{O}_{3}$ nanoparticles $-2.2 \%$ and $3.7 \%$, respectively. It should be noted that a decrease in the heat capacity and changes in the melting heat due to the presence of nanoparticles in the liquid and solid phases of substances are mentioned in some studies $[13,14]$. Such changes can be considered as a negative factor for nanostructured substances that are promising as thermal storage PCMs.

The study [7] reported that a composite of expanded perlite (40 wt. \%)/n-eicosane (paraffin)/carbon nanotubes (1 wt. \%) has an apparent improving effect on the thermal conductivity without considerably affecting the compatibility of the components and thermal stability compared to the mixture of expanded perlite/n-eicosane. However, the presence of perlite that acts as a skeleton for the retention of paraffin inside pores will lead to a decrease in the heat of phase transition for composite thermal storage PCM and therefore it can be interpreted as an undesirable effect. At the same time, the system of nanotubes/paraffin has low stability: it is a well-known fact that high length-to-diameter ratio and high surface energy make carbon nanotubes easily aggregate in thermal storage PCMs [8]. For further application in the industry, carbon nanotubes should be modified to improve their dispersion in thermal storage PCMs and the thermal conductivity of the obtained composite materials [8].

The 3D carbon-based materials (carbon foam and expanded graphite) have a spatial network structure that causes an increase in the contact areas with thermal storage PCM and contributes to the thermal conductivity enhancement of composite thermal storage PCM [8]. In [9], four types of carbon materials (biochar, activated carbon, carbon nanotubes, and expanded graphite) were applied to produce composite thermal storage PCM containing heptadecane (paraffin). The pores in the mentioned carbon materials were filled using a vacuum impregnation technique. Among the considered carbon materials, expanded graphite had the highest PCM content $-94.5 \%$. Composite PCM based on expanded graphite had the highest latent heat of melting $\left(195.9 \mathrm{~J} \cdot \mathrm{g}^{-1}\right)$.

However, the use of carbon-based composite PCMs in the industry is still insignificant due to the high cost and reduction of mechanical properties [8].

In [10], a new type of porous material - a metal hierarchical 3D macro-nanoporous material - was investigated to stabilize the shape and increase the thermal conductivity of thermal storage PCM. Due to the presence of macropores in metal (copper), the completeness of pores filling by PCM (PW) was evaluated as approximately $90 \mathrm{vol}$. \%. It was shown that the use of a macro-nanoporous metal structure leads to a threefold increase in the thermal conductivity for composite PCM compared to pure PCM [10]. However, macro-nanoporous metals are currently expensive, and therefore it is urgent to find cheaper, but no less effective additives to thermal storage PCMs.

In [11], the authors have reported that metal wool can be used as a low-cost additive to increase the thermal conductivity of thermal storage PCMs. It was established that to achieve an increase in the effective thermal conductivity of composite PCM (epoxy resin of $90 \mathrm{vol} . \%$ and stainless steel), it is advisable to perform evacuation when producing new material. The obtained composite PCM had an anisotropic effective thermal conductivity similar to graphite composites. The measured effective thermal conductivity of composite PCM was equal to $4.34 \mathrm{~W} \cdot \mathrm{m}^{-1} \cdot \mathrm{K}^{-1}$, while for epoxy resin it was very low - typically about $0.2 \mathrm{~W} \cdot \mathrm{m}^{-1} \cdot \mathrm{K}^{-1}$. However, the lack of this study is the fact that industrial-grade PW was not considered as thermal storage PCM and only one type of metal wool of only one volume fraction was investigated.

In [12], an investigation of four heat dissipation methods from lithium-ion batteries at different discharge currents was performed: natural air cooling, heat dissipation with pure PW, copper foam/PW composite and copper wool/PW composite. The results of the analysis of four thermal storage PCM samples with porosity from 83.7 to $96.1 \%$ have shown that the use of a sintered skeleton from copper wool with a porosity of $90 \%$ provides the best characteristics of the composite material. Composite copper wool/PW PCM can effectively absorb the heat released during accumulator battery operation, which reduces its temperature by about $2{ }^{\circ} \mathrm{C}$ compared to pure PW. However, the mentioned study did not consider any options of using cheaper aluminum wool.

Metal wool and carbon nanomaterials are two most common components used to improve the thermal conductivity of thermal storage PCMs due to high thermal conductivity and low density [3-5]. Despite of the fact that carbon nanomaterials have high chemical stability and low corrosion activity, their application has two disadvantages. The first problem is a significant increase in the cost of composite PCMs. The second problem is the low stability of a uniform distribution of carbon nanoparticles in PCM under cyclic thermal loading of the TES device. Based on the performed review, it was decided to focus on evaluating the feasibility of using metal wool as additives to thermal storage PCMs, considering the fact that this material is cheap and effective. A review of the experimental studies has 
demonstrated that the use of metal wool as additives to PCMs leads to an increase in the thermal conductivity and, consequently, efficiency of TES systems. But comprehensive assessment of the influence of various types of metal wool and their different content in PW as thermal storage PCM still remains insufficiently examined.

\section{Research aim and objectives}

This work aimed to evaluate the effect of metal wool in PW on the rate of charging (heating) and discharging (cooling) of composite thermal storage PCM samples. A rational choice of types of metal wool and their quantity makes it possible to increase the reaction rate for the thermal storage material to the thermal influences and to increase the overall efficiency of a TES system.

To achieve the aim, the following objectives have been set:

- to create an experimental setup for studying the rate of heating and cooling of composite thermal storage PCMs;

- to perform an experimental study of the effect of metal wool in PW on the rate of its temperature change during heating and cooling in two modes: with solid-liquid phase transition and without phase transition.

\section{Research materials and methods}

The following materials have been used to prepare composite thermal storage PCMs:

- paraffin wax (industrial grade T-3, melting temperature $53.5^{\circ} \mathrm{C}$ ), made in Poland;

- aluminum wool with an average fiber diameter of $30 \mu \mathrm{m}$ (the supplier - Ekksol, made in Germany), a thermal conductivity (according to passport) $168 \mathrm{~W} \cdot \mathrm{m}^{-1} \cdot \mathrm{K}^{-1}$, base element content - not less than $0.922 \mathrm{~kg} \cdot \mathrm{kg}^{-1}$;

- copper wool with an average fiber diameter of $45 \mu \mathrm{m}$ (the supplier - Ekksol, made in Germany), the thermal conductivity (according to passport) $383 \mathrm{~W} \cdot \mathrm{m}^{-1} \cdot \mathrm{K}^{-1}$, base element content - not less than $0.999 \mathrm{~kg} \cdot \mathrm{kg}^{-1}$.

A picture of the PW samples containing metal wool (in pellet form with diameters $23 \ldots 25 \mathrm{~mm}$ and thickness 4.5...5.5 mm) is presented in Fig. 1.

The samples of composite PCMs were prepared by laying some amount of metal wool into a measuring cell of cylindrical shape, followed by filling it with molten PW at a temperature of $70{ }^{\circ} \mathrm{C}$. The required quantity of the components for composite PCM was measured using the GR 300 electronic analytical balance with an instrumental error of $0.5 \mathrm{mg}$.

Table 1 presents the main characteristics of the PCM samples that were used in the experiments.

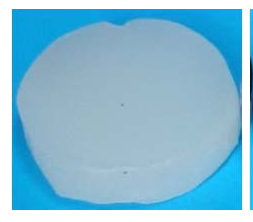

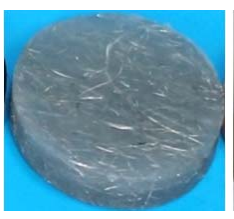

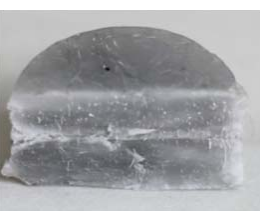

c

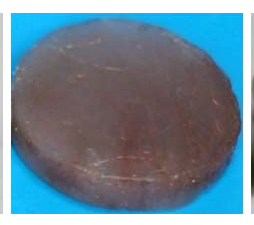

Characteristics of the PCM samples - the research objects

\begin{tabular}{|c|c|c|c|c|}
\hline $\begin{array}{c}\text { Labeling in } \\
\text { the figures } \\
\text { and text }\end{array}$ & $\begin{array}{c}\text { Metal } \\
\text { wool }\end{array}$ & $\begin{array}{c}\text { Metal } \\
\text { wool } \\
\text { mass, } \mathrm{kg}\end{array}$ & $\begin{array}{c}\text { Metal wool } \\
\text { mass frac- } \\
\text { tion, } \mathrm{kg} \cdot \mathrm{kg}^{-1}\end{array}$ & $\begin{array}{c}\text { Metal wool } \\
\text { volume frac- } \\
\text { tion, } \mathrm{m}^{3} \cdot \mathrm{m}^{-3}\end{array}$ \\
\hline $\mathrm{PW}$ & - & - & - & - \\
\hline $\mathrm{PW}+\mathrm{Al} \mathrm{I}$ & Aluminum & 0.1533 & 0.0174 & 0.00588 \\
\hline $\mathrm{PW}+\mathrm{Al} \mathrm{II}$ & Aluminum & 0.4702 & 0.0515 & 0.01780 \\
\hline $\mathrm{PW}+\mathrm{Cu} \mathrm{I}$ & Copper & 0.4538 & 0.0498 & 0.00524 \\
\hline $\mathrm{PW}+\mathrm{Cu}$ II & Copper & 1.2049 & 0.1222 & 0.01380 \\
\hline
\end{tabular}

The previous experimental study [15] of PW containing aluminum or copper wool has shown a significant increase in the thermal conductivity of the composite PCM samples in the solid phase vs pure PW - Table 2.

Table 2

Thermal conductivity of PW-based composite PCMs containing metal wool [15]

\begin{tabular}{|c|c|c|c|}
\hline Material & PW & $\mathrm{PW}+\mathrm{Al}$ & $\mathrm{PW}+\mathrm{Cu}$ \\
\hline $\begin{array}{c}\text { Metal wool mass } \\
\text { fraction, } \mathrm{kg} \cdot \mathrm{kg}^{-1}\end{array}$ & 0 & $0.285 \pm 0.011$ & $0.756 \pm 0.150$ \\
\hline $\begin{array}{c}\text { Metal wool } \\
\text { volume fraction, } \\
\mathrm{m}^{3} \cdot \mathrm{m}^{-3}\end{array}$ & 0 & $0.00968 \pm 0.00037$ & $0.00818 \pm 0.00175$ \\
\hline $\begin{array}{c}\text { Thermal conduc- } \\
\text { tivity, } \mathrm{W} \cdot \mathrm{m}^{-1} \cdot \mathrm{K}^{-1}\end{array}$ & $0.256 \pm 0.0030$ & $0.455 \pm 0.034$ & $0.328 \pm 0.086$ \\
\hline
\end{tabular}

An interesting result was obtained in terms of expediency of industrial application of PW samples containing metal wool (Table 1). It was shown that a higher increase in the thermal conductivity for the $\mathrm{PW}+\mathrm{Al}$ vs $\mathrm{PW}+\mathrm{Cu}$ samples is reached at a smaller mass fraction of aluminum wool in comparison with copper wool. It should also be noted that aluminum wool has lower thermal conductivity and lower cost than copper one. Therefore, using aluminum wool is better justified in terms of further practical application in composite thermal storage PCMs in the industry.

The further study of the rate of charging (heating) and discharging (cooling) of the measuring cell filled with the studied thermal storage PCMs was performed on the original experimental setup.

\section{Results of investigation of the heating and cooling rates} for the metal wool armored paraffin wax samples

5. 1. Experimental setup and measurements technique

An experimental study of the effect of metal wool added to the PW samples on the rate of charging (heating) and discharging (cool-

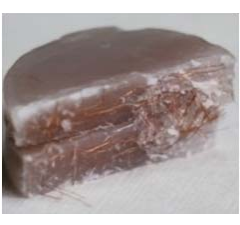

Fig. 1. Picture of the composite thermal storage PCM samples: $a-$ pure $\mathrm{PW}, b-\mathrm{PW}$ containing $0.285 \pm 0.011 \mathrm{~kg} \cdot \mathrm{kg}^{-1}\left(0.00968 \pm 0.00038 \mathrm{~m}^{3} \cdot \mathrm{m}^{-3}\right)$ of aluminum wool; $c-$ cut sample $b ; d-\mathrm{PW}$ containing $0.756 \pm 0.150 \mathrm{~kg} \cdot \mathrm{kg}^{-1}\left(0.00818 \pm 0.00174 \mathrm{~m}^{3} \cdot \mathrm{m}^{-3}\right)$ of cooper wool; $e-$ cut sample $d$ ing) of the obtained PCM samples was performed using the experimental setup shown in Fig. 2. The main elements of the experimental setup were measuring cell 4 filled with the studied PCM samples 5 and two liquid thermostats 6 and 10 that maintain different thermostating temperatures. 


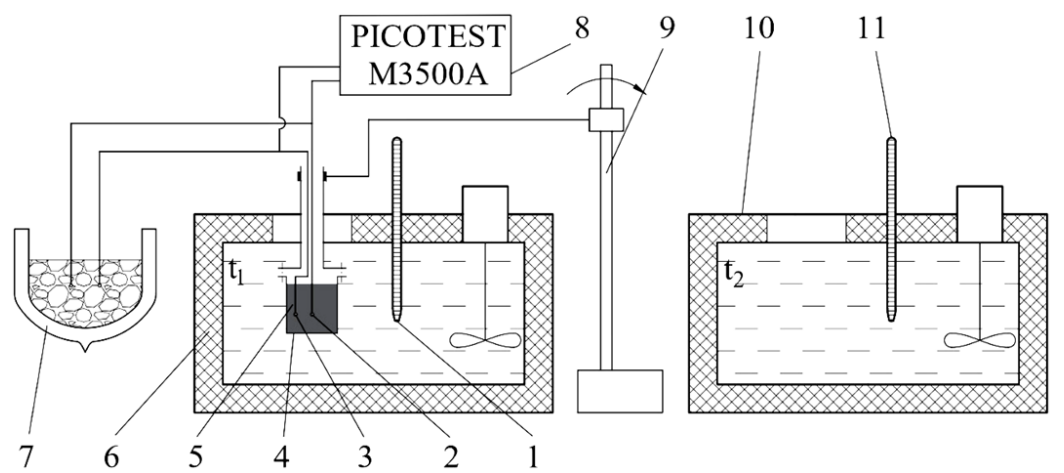

Fig. 2. Scheme of the experimental setup for investigating the rate of charging and discharging of the cell (capsule) containing PCM: 1, 11 - laboratory thermometers; 2, 3 - thermocouples; 4 - copper measuring cell; 5 - PCM sample;

6, 10 - thermostats; 7 - Dewar vessel with ice to maintain a temperature of $0{ }^{\circ} \mathrm{C} ; 8$ - multimeter; 9 - cell holder

The measuring cell 5 is made of copper. The design of measuring cell 5 is shown in Fig. 3. To study the rate of temperature change in the PCM samples, two absolute copper-constantan thermocouples 2 and 3 were installed into thin-walled metal capillaries. The thermocouples were installed in the middle of the height of the measuring cell: 2 - in the center of the cell and 3 - near the cell wall $(1.0 \mathrm{~mm}$ from the wall). Thermocouple readings were recorded with a Pisotest M3500A multimeter (Taiwan).

In addition, the presence of metal fins leads to a decrease in the mass of PCM in the TES device and, as a consequence, the energy capacity.

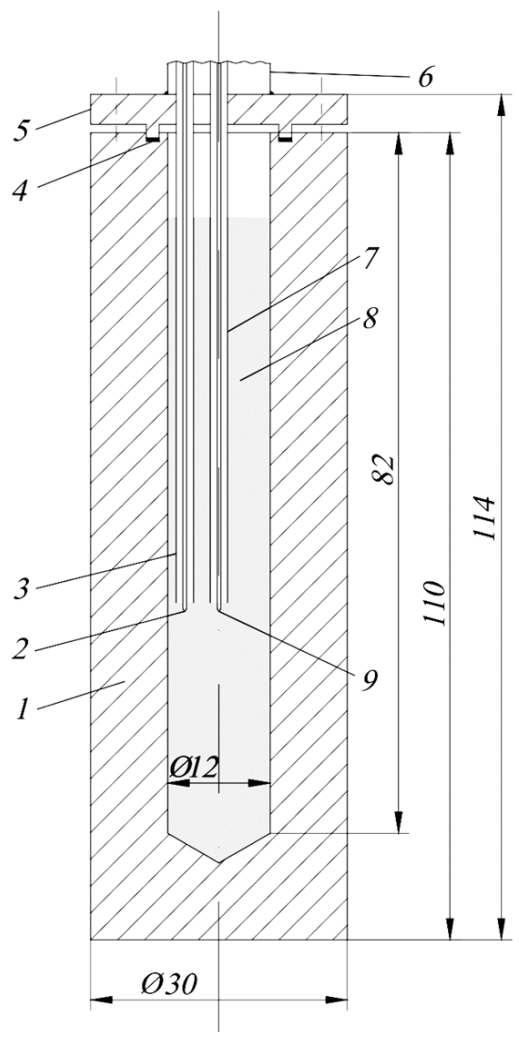

Fig. 3. Scheme of the measuring cell for investigating charging and discharging processes of composite PCM: 1 - copper shell; 2, 9 - thermocouples; 3, 7 - thin-walled capillaries; 4 - sealing gasket; 5 - cover; 6 - tube; 8 - PCM sample
The experiment was performed in two stages. At the first one, the temperatures $t_{1}$ and $t_{2}\left(t_{1}>t_{2}\right)$ were set in thermostats 6 and 10, respectively. Cell 4 was cooled in thermostat 6 until reaching $t_{2}$ in the center of the cell. After that, cell 4 was immersed in thermostat 6 for heating (simulation of the process of charging the capsule with PCM) with the simultaneous turning on the system of automatic recording of the thermocouples 2 and 3 readings with an interval of $1 \mathrm{~s}$. After reaching $t_{1}$ in the center of cell 4 , the cell was moved to thermostat 10 for cooling (simulation of the process of discharging the capsule with PCM), followed by recording the change in the readings of thermocouples 2 and 3 in time. The experiment was conducted at convection boundary conditions (i.e. at the constant heat transfer coefficient from cell to water in the thermostat). The thermal resistances both of the measuring cell wall and heat transfer from water to the wall were insignificant compared to the thermal resistance of the PCM layer in the cell.

Two modes have been experimentally investigated:

1) the measuring cell filled with the PCM sample was heated from 48 to $59{ }^{\circ} \mathrm{C}$ in the center of the cell after dipping it into the water of $59{ }^{\circ} \mathrm{C}$ and after that, the cell was cooled from 59 to $48{ }^{\circ} \mathrm{C}$ after dipping it into the water of $48^{\circ} \mathrm{C}$; in this mode, the phase transition in the PCM sample was expected;

2) the measuring cell filled with the PCM sample was heated from 30 to $40{ }^{\circ} \mathrm{C}$ in the center of the cell dipping it into the $40{ }^{\circ} \mathrm{C}$ water and after that, the cell was cooled from 40 to $30^{\circ} \mathrm{C}$ after dipping it into the water of $30{ }^{\circ} \mathrm{C}$; in this mode, phase transitions in the PCM sample were not expected.

5. 2. The rate of heating and cooling of the PW samples containing metal wool

Fig. 4 shows the change of the PW sample temperature in two points of the measuring cell (in the center and near the wall) during its charging (heating) and discharging (cooling) processes in the phase transition mode. Fig. 5-8 show the temperature change of the research objects in the center of the measuring cell with time during the charging and discharging processes. The temperature-time dependence for pure PW was used as a baseline characteristic temperature dependence to assess the influence of metal wool of different content on the composite PCM heating and cooling rates and phase transition parameters. Obviously, the temperature field in the cylindrical measuring cell always has a symmetric shape around the cell axis. 


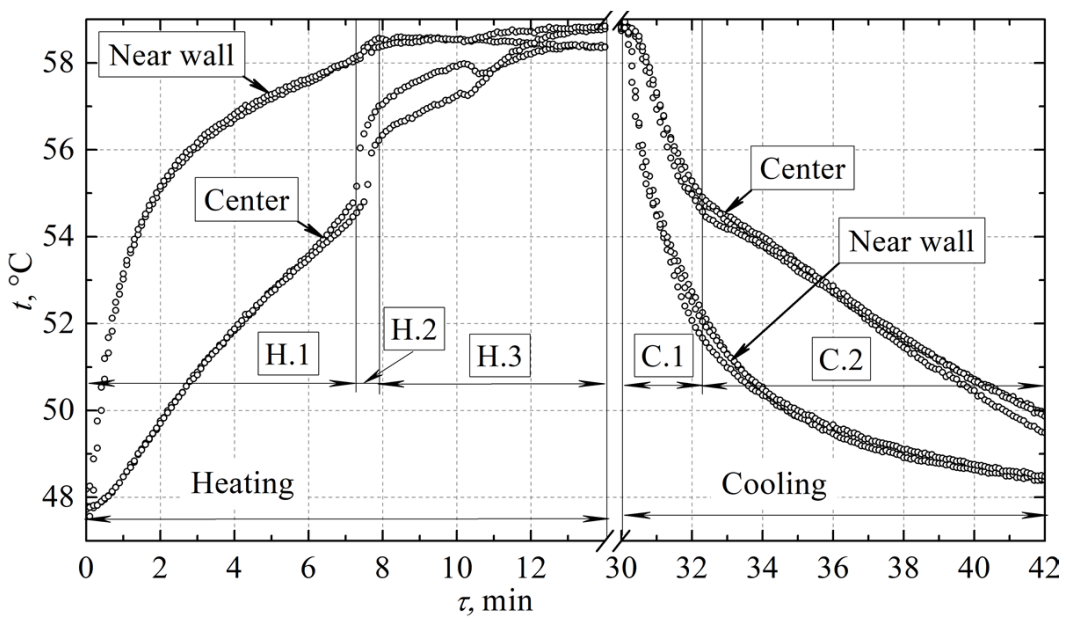

Fig. 4. Time dependence of the PW sample temperature in the center of the measuring cell and near its wall during heating and cooling in the phase transition mode

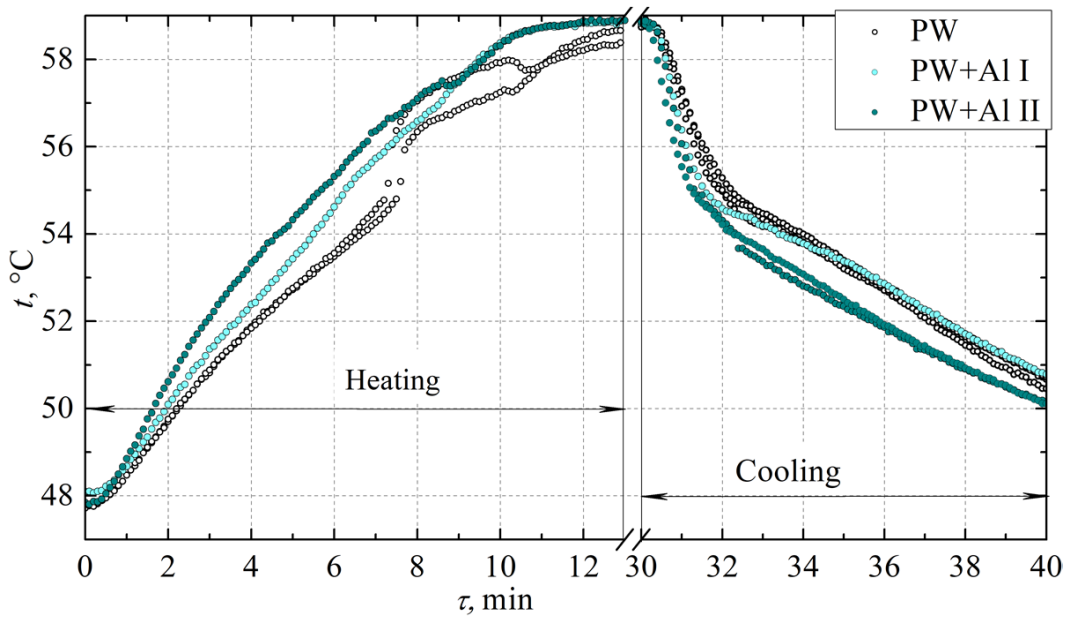

Fig. 5. Temperature-time dependence in the center of the measuring cell containing the PW, PW+AI I, and PW+AI II samples during heating and cooling in the phase transition mode

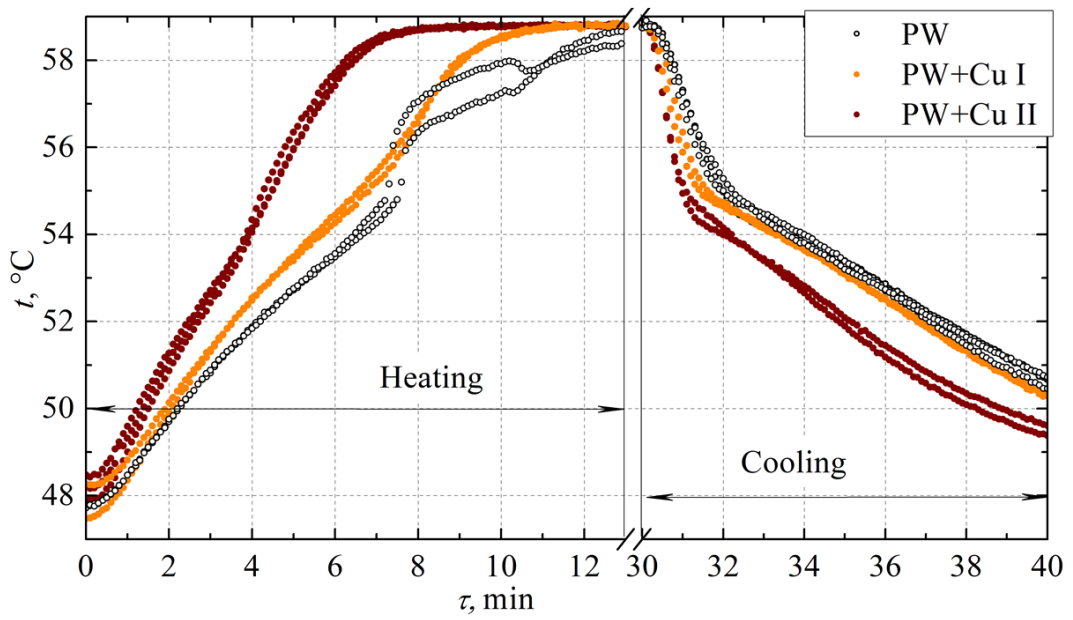

Fig. 6. Temperature-time dependence in the center of the measuring cell containing the PW, PW+Cu I, and PW+Cu II samples during heating and cooling in the phase transition mode

Fig. 5-8 imply that all of the studied samples of PCMs containing metal wool have higher heating and cooling rates compared to pure PW both in the mode with the phase transition and in the mode without one. 


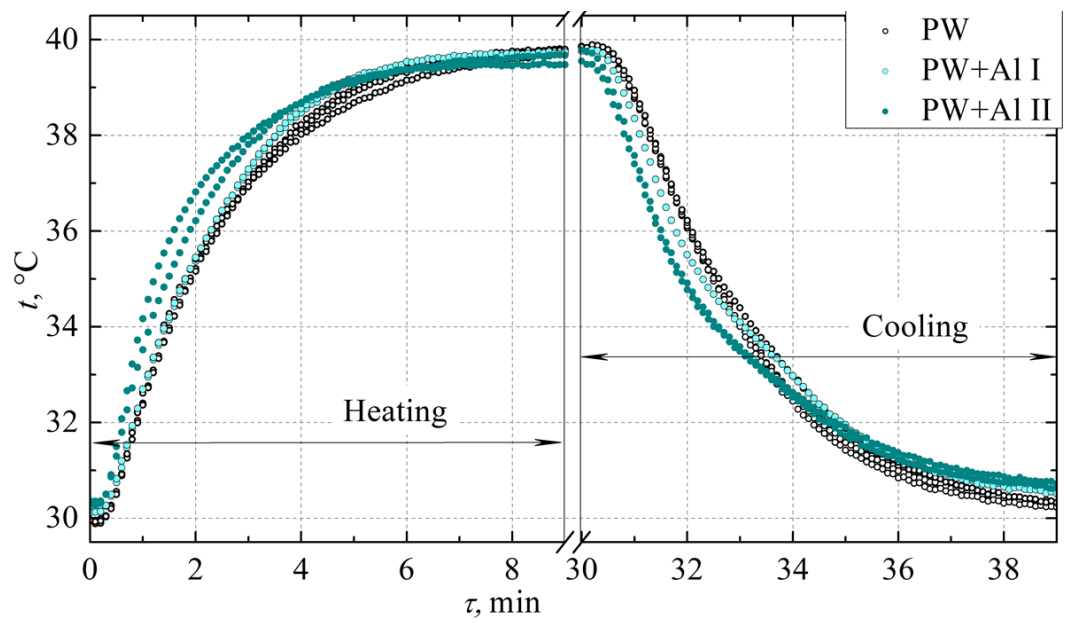

Fig. 7. Temperature-time dependence in the center of the measuring cell containing the PW, $P W+A I I$, and $P W+A I I I$ samples during heating and cooling in the mode without phase transition

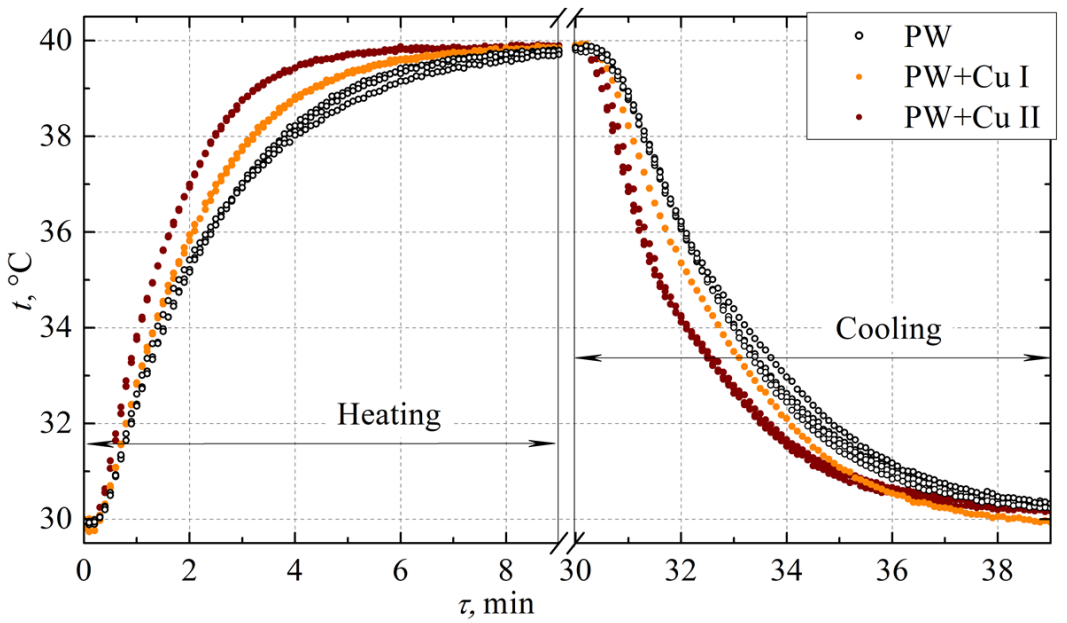

Fig. 8. Temperature-time dependence in the center of the measuring cell containing the PW, PW+Cu I, and PW+Cu II samples during heating and cooling in the mode without phase transition

\section{Discussion of the results of the study of heating and cooling rates of the $\mathrm{PW}$ samples containing metal wool}

Analyzing the temperature-time dependence in the center of the PW sample during its charging (Fig. 4), three stages can be selected. On the first stage (H.1), the PW was in a solid state in the center of the measuring cell. This area is gradually heated by supplying heat through the concentric layers of already melted (near the cell wall) and not yet melted (in the center of the cell) PW. Thus, in the charging process, two areas coexist: the area of molten PCM and the area of solid one. In the solid area, the thermal conductivity inside the solid PCM is responsible for the heat transfer process, and this area receives heat from the melted area by convection. Melting starts in the area close to the inner cell wall, then the molten PCM can ascend to the top of the cell due to natural convection - Fig. 9 (H.1). The second stage (H.2) is characterized by reaching the melting point in the center of the sample. At the same time, there is a rapid change in the temperature of the central area by about $1{ }^{\circ} \mathrm{C}$ for a very short time (Fig. 4). Probably this is due to the convective heat supplied by currents of the molten PW from the top of the cell - Fig. 9 (H.2). The liquid PW at the top of the cell is overheated relative to its melting point. There were also slight temperature fluctuations at this moment (H.2) near the wall (Fig. 4). These oscillations can be explained by the redistribution of convective currents due to the disappearance of the obstacle to their circulation (solid phase in the center of the cell). In the third stage (H.3), there is a decrease in the rate of heating of the molten PW. This is primarily due to the reduction of the temperature difference between the heating medium (water in thermostat 6) and the PW, as well as the contribution of free convection to the smoothing of the temperature field.

Analyzing the discharging (cooling) process (Fig. 4) in its first stage (C.1), a rapid temperature decrease in the center of the PW sample can be seen. This can be explained by both a significant temperature gradient by a thickness of the concentric layer of the PW in the measuring cell (difference between the readings of thermocouples 2 and 3 in Fig. 2) and convective currents in the PW, which is still liquid. When the PW temperature in the center of the cell reaches approximately $55^{\circ} \mathrm{C}$, the cooling rate decreases. This happens since the bulk of the PW has been already solidified, and the small cylindrical volume left in the center is no longer sufficient for natural convection, so it can not significantly affect the 
heat dissipation process. At this point, the second stage (C.2) of cooling the PW sample in the cell starts, which is characterized by the low rate due to the small temperature difference between the PW and the cooling medium and the heat transfer exclusively provided by the thermal conductivity.

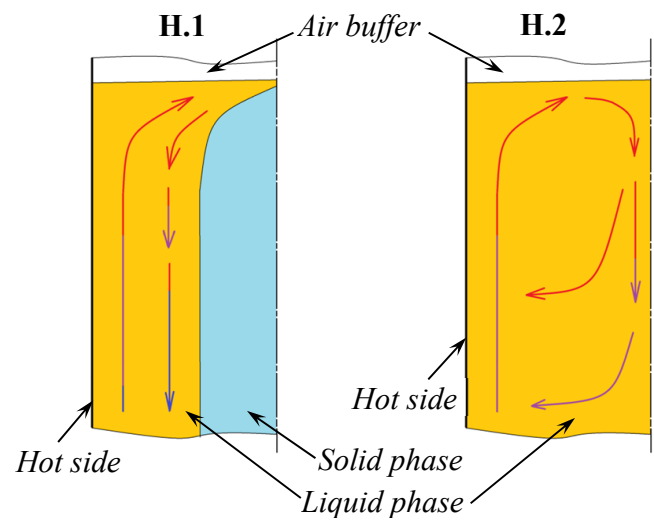

Fig. 9. Scheme of convective currents of the molten PW in the measuring cell during heating in the phase transition mode

As expected, with an increase in the metal wool mass fraction, the heating and melting of the PCM samples of equal volumes require less time - see Fig. 5-8. The melting and heating duration from 48 to $59{ }^{\circ} \mathrm{C}$ for the $\mathrm{PW}$ and the composite $\mathrm{PCM}$ samples of $\mathrm{PW}+\mathrm{Al} \mathrm{I}, \mathrm{PW}+\mathrm{Al} \mathrm{II}, \mathrm{PW}+\mathrm{Cu} \mathrm{I}$, $\mathrm{PW}+\mathrm{Cu}$ II were determined as about 13, 11, 10.5, 11, 8 minutes, respectively (Fig. 5,6). This result confirms that the heating rate (including melting) of composite PCMs containing copper wool is significantly reduced compared to pure PW. Similarly, the effect of an increase in the heating rate of composite PMCs in the temperature mode without phase transitions (Fig. 7, 8) is observed. As in the mode with the phase transition, the highest heating rate from 30 to $40{ }^{\circ} \mathrm{C}$ was observed for the $\mathrm{PW}+\mathrm{Cu}$ II sample: about 6 minutes vs 9 minutes for the pure PW sample.

The reduction in times for the heating and melting of the composite PCM samples containing metal wool confirmed the improvement of the effective thermal conductivity. The higher was the metal wool mass fraction (both aluminum and copper), the higher was the heat transfer rate as a result of the reduction of the thermal resistance of the PCM layer near the wall of the measuring cell. It should be noted that in the experiment, the thermal resistance of the wall of the measuring cell and that of the heat transfer from water to the wall were less than the thermal resistance of the PCM layer in the cell. It should also be mentioned (Fig. 5-8) that both samples of $\mathrm{PW}+\mathrm{Cu}$ have higher heating rates than $\mathrm{PW}+\mathrm{Al}$ at the approximately equal volume contents of metal wool (Table 1). Previous studies of the thermal conductivity of the composite materials $\mathrm{PW}+\mathrm{Al}$ and $\mathrm{PW}+\mathrm{Cu}$ (Table 2) at the volume content of aluminum wool in PW by $15 \%$ more than copper showed an increase in the thermal conductivity of $\mathrm{PW}+\mathrm{Al}$ by $28 \%$ compared to $\mathrm{PW}+\mathrm{Cu}$. This discrepancy can be explained by the fact that the thermal conductivity of the samples of anisotropic materials is affected not only by the thermal conductivity of the additives but also by the nature of packaging of these additives in the base material (PW). Therefore, the effect of metal wool additives on the thermal conductivity of composite thermal storage $\mathrm{PCM}$ requires further examination.

As can be seen from Fig. 5, 6, the temperature-time dependence in the center of the cell with the composite PCM samples in the process of charging (heating) is smoother than when heating pure PW. Therefore, there is reason to believe that metal wool contained in PCMs partially suppresses bottom-up natural convective currents. Thus, the main mechanism of heat transfer in the liquid phase is thermal conductivity. Moreover, two factors contribute to increasing the effective thermal conductivity of composite PCM: heat transfer through metal wool and microconvective currents of the molten PW inside the structure formed by metal wool. This is indirectly confirmed by the following observations. First, it is the absence of the region H.2 on the temperature-time dependence for the composite PCM samples during heating (Fig. 5, 6). Second, it is a smaller effect of metal wool on the heating rate of the composite PCM samples in the mode without phase transitions (in this case, the effect of microconvection is absent). Similarly, analyzing the process of discharging (cooling) of the composite PCM samples (Fig. 7, 8), there is a faster rate of cooling of the molten $\mathrm{PW}$ in stage C.1. At the end of this stage, a lower temperature is achieved compared to the sample of pure PW. This phenomenon can be explained by the fact that radial heat transfer is not hindered by bottom-up convective currents.

The obtained results are of great practical importance for the following reasons:

- the composite PCM samples considered in this study can more rapidly absorb the heat supplied from heat sources compared to pure PW as PCM;

- due to the uneven temperature distribution by the height of vertical containers with PCMs [16], the use of PW containing metal wool will contribute to the faster smoothing of the temperature field.

Based on the presented analysis, the feasibility of future studying the prospects of using copper and aluminum wool as additives to PW to find their most rational contents in composite thermal storage PCMs can be stated. The results of the performed study have not allowed yet to establish a quantitative relationship between the obtained data and the thermal conductivity values of the studied PCMs presented in [15]. This fact indicates the multifactorial effect of metal wool on the charging and discharging processes of composite PCMs. In addition, the possibility of modeling the processes of charging and discharging a capsule filled with PCMs based only on the thermophysical properties of PCMs containing metal wool remains unclear (taking into account the anisotropy of the transport properties of such systems). This issue also needs further study. For the final interpretation of the obtained results, measurements of the caloric properties for pure PW and PW containing metal wool should be performed. This information is needed to be sure that the considered PCMs containing metal wool have a high thermal energy storage density. From a practical point of view, their thermal energy storage density shouldn't be lower than that of pure PW, and an increase in the cost due to the addition of the most rational amount of metal wool should be slight. 


\section{Conclusions}

1. The experimental setup for investigating the heating and cooling rates of composite thermal storage PCMs based on PW containing metal wool was created. The main element of the experimental setup was a copper cylindrical measuring cell filled with composite PCM, which can be considered as a model of the capsule of the TES system. A feature of the setup was performing the experiment in conditions close to those used in practice. This eliminates the need for any additional complex experiments to measure the thermophysical properties, followed by computational modeling of the heating or cooling processes for the studied samples.

2. The experimental measurements of temperature-time dependences in two points of the measuring cell filled with the samples of pure PW and PW containing metal wool were performed. Two modes of heating and cooling of the samples were studied: from 48 to $59{ }^{\circ} \mathrm{C}$ (mode with phase transitions) and from 30 to $40{ }^{\circ} \mathrm{C}$ (mode without phase transitions). The melting and heating durations from 48 to $59{ }^{\circ} \mathrm{C}$ were determined as about 13 minutes for the sample of pure PW. For the samples of PW containing 0.00588 and $0.01780 \mathrm{~m}^{3} \cdot \mathrm{m}^{-3}$ of aluminum wool, the heating times were lower - about 11 and 10.5 minutes, respectively. For the samples of PW containing 0.00524 and $0.01380 \mathrm{~m}^{3} \cdot \mathrm{m}^{-3}$ of cooper wool, the heating times were about 11 and 8 minutes, correspondingly. The highest heating rate in the range from 30 to $40{ }^{\circ} \mathrm{C}$ was about 6 minutes for the PW sample containing $0.01380 \mathrm{~m}^{3} \cdot \mathrm{m}^{-3}$ of copper wool vs to 9 minutes for the pure PW sample. It was found that an increase in the metal wool mass fraction in the considered composite PCMs leads to a decrease in the duration of the heating and cooling processes in both modes with phase transition in PCM and without one. Moreover, at the equal metal wool volume fractions, the use of copper gives a greater effect than aluminum. The obtained effects confirm the improvement in the effective thermal conductivity of PW containing metal wool compared to pure PW. Metal wool added to PW partially suppresses bottom-up natural convective currents when the PCM is melted. Thus, the main mechanism of heat transfer in the liquid phase of composite thermal storage PCMs containing metal wool is thermal conductivity. The increase in the effective thermal conductivity of composite PCMs is explained by heat transfer through metal wool and microconvective currents inside the structure formed by wool (for molten PCMs). The predominance of heat transfer by the thermal conductivity for composite PCMs in the molten state will promote a faster smoothing of the temperature field by the height of elements of the TES system.

\section{Acknowledgments}

The authors are grateful to the National Research Foundation of Ukraine, project No. 2020.02/0125, for financial support of this study.

\section{References}

1. Javadi, F. S., Metselaar, H. S. C., Ganesan, P. (2020). Performance improvement of solar thermal systems integrated with phase change materials (PCM), a review. Solar Energy, 206, 330-352. doi: https://doi.org/10.1016/j.solener.2020.05.106

2. Kahwaji, S., Johnson, M. B., Kheirabadi, A. C., Groulx, D., White, M. A. (2018). A comprehensive study of properties of paraffin phase change materials for solar thermal energy storage and thermal management applications. Energy, 162,1169-1182. doi: https:// doi.org/10.1016/j.energy.2018.08.068

3. Gasia, J., Maldonado, J. M., Galati, F., De Simone, M., Cabeza, L. F. (2019). Experimental evaluation of the use of fins and metal wool as heat transfer enhancement techniques in a latent heat thermal energy storage system. Energy Conversion and Management, 184, 530-538. doi: https://doi.org/10.1016/j.enconman.2019.01.085

4. Nie, C., Deng, S., Liu, J. (2020). Effects of fins arrangement and parameters on the consecutive melting and solidification of PCM in a latent heat storage unit. Journal of Energy Storage, 29, 101319. doi: https://doi.org/10.1016/j.est.2020.101319

5. Rostami, S., Afrand, M., Shahsavar, A., Sheikholeslami, M., Kalbasi, R., Aghakhani, S. et. al. (2020). A review of melting and freezing processes of PCM/nano-PCM and their application in energy storage. Energy, 211, 118698. doi: https://doi.org/10.1016/ j.energy.2020.118698

6. Manoj Kumar, P., Sudarvizhi, D., Stalin, P. M. J., Aarif, A., Abhinandhana, R., Renuprasanth, A. et. al. (2021). Thermal characteristics analysis of a phase change material under the influence of nanoparticles. Materials Today: Proceedings, 45, 7876-7880. doi: https:// doi.org/10.1016/j.matpr.2020.12.505

7. Karaipekli, A., Biçer, A., Sarı, A., Tyagi, V. V. (2017). Thermal characteristics of expanded perlite/paraffin composite phase change material with enhanced thermal conductivity using carbon nanotubes. Energy Conversion and Management, 134, 373-381. doi: https://doi.org/10.1016/j.enconman.2016.12.053

8. Li, M., Mu, B. (2019). Effect of different dimensional carbon materials on the properties and application of phase change materials: A review. Applied Energy, 242, 695-715. doi: https://doi.org/10.1016/j.apenergy.2019.03.085

9. Atinafu, D. G., Yun, B. Y., Wi, S., Kang, Y., Kim, S. (2021). A comparative analysis of biochar, activated carbon, expanded graphite, and multi-walled carbon nanotubes with respect to PCM loading and energy-storage capacities. Environmental Research, 195, 110853. doi: https://doi.org/10.1016/j.envres.2021.110853

10. Grosu, Y., Zhao, Y., Giacomello, A., Meloni, S., Dauvergne, J.-L., Nikulin, A. et. al. (2020). Hierarchical macro-nanoporous metals for leakage-free high-thermal conductivity shape-stabilized phase change materials. Applied Energy, 269, 115088. doi: https:// doi.org/10.1016/j.apenergy.2020.115088 
11. Prieto, C., Lopez-Roman, A., Martínez, N., Morera, J. M., Cabeza, L. F. (2021). Improvement of Phase Change Materials (PCM) Used for Solar Process Heat Applications. Molecules, 26 (5), 1260. doi: https://doi.org/10.3390/molecules26051260

12. Pan, M., Lai, W. (2017). Cutting copper fiber/paraffin composite phase change material discharging experimental study based on heat dissipation capability of Li-ion battery. Renewable Energy, 114, 408-422. doi: https://doi.org/10.1016/j.renene.2017.07.004

13. Zhelezny, V., Motovoy, I., Khliyeva, O., Lukianov, N. (2019). An influence of Al2O3 nanoparticles on the caloric properties and parameters of the phase transition of isopropyl alcohol in solid phase. Thermochimica Acta, 671, 170-180. doi: https:// doi.org/10.1016/j.tca.2018.11.020

14. Zhelezny, V., Khliyeva, O., Motovoy, I., Lukianov, N. (2019). An experimental investigation and modelling of the thermal and caloric properties of nanofluids isopropyl alcohol - Al2O3 nanoparticles. Thermochimica Acta, 678, 178296. doi: https://doi.org/10.1016/ j.tca.2019.05.011

15. Khliyeva, O. Ya., Nikulin, A. G., Zhelezny, V. P., Paskal, A. A., Semenyuk, Yu. V. (2021). Thermal conductivity of metal wool armored phase change materials for thermal energy storage. Int. conf.: Functional materials for innovative energy. Kyiv, 8.

16. Punniakodi, B. M. S., Senthil, R. (2021). A review on container geometry and orientations of phase change materials for solar thermal systems. Journal of Energy Storage, 36, 102452. doi: https://doi.org/10.1016/j.est.2021.102452 